\title{
À sombra do imortal: reflexões sobre a nação e a memória
}

\section{Elias Thomé Saliba}

Departamento de História, Faculdade de Filosofia, Letras e Ciências Humanas/Universidade de São Paulo
Regina Abreu. A fabricação do imortal: memória, história e estratégias de consagração no Brasil. Rio de Janeiro: Rocco/Lapa, 1996. "Durante uma viagem perdi o chapéu, capote, luvas, carteira, lenço e toda a bagagem de mão.
Fouqué perguntoume se eu não havia perdido a sombra e assim ficamos imaginando a desgraça
que isso seria" (Adelbert von Chamisso, 1813).

O homem sem sombra, da proto-kafkeana fábula de Chamisso, parece impor uma tensão enorme à razão contemporânea pois, além da ambigüidade infinita de significados da parábola do homem que perdeu sua sombra, parece impingir-nos a figura inquietante do indivíduo sem memória, sem identidade e sem nação - portanto, sem possibilidade de superar a tragédia da mortalidade e o sono profundo do esquecimento. Podemos lembrar ainda o que, ironicamente, Chamisso escreveu no prefácio da edição francesa do seu Schlemihl. Transcrevendo a definição de sombra de um alfarrábio antigo, que, de forma oblíqua, dizia que "a sombra propriamente dita representava um sólido cuja forma depende, ao mesmo tempo, do corpo luminoso, do corpo opaco e da posição deste em relação ao corpo luminoso", Chamisso terminava com uma recomendação ainda mais sibilina aos sábios coetâneos: Pensai no sólido!' Como metáfora da solidez da cultura de uma classe mas, também, símbolo da agregação humana e da nacionalidade invisivel de cada homem, a sombra constituía parte do projeto difusamente iluminista de Chamisso.
1. O parágrafo completo de Chamisso, depois de transcrever a irônica definiçào de "sombra", é o seguinte: "É desse sólido que se trata na história maravilhosa de Peter Schlemihl. A ciência das finanças instrui-nos suficientemente sobre a importância do dinheiro; a da sombra é menos reconhecida no geral. Meu imprudente amigo cobiçou o dinheiro, cujo valor ele reconhecia, e não pensou no sólido. A lição que pagou caro -- ele quer que nós á aproveitemos e sua experiência nos conclama: pensai no sólido!" (Chamisso 1989: 108-9). 
Já no cenário de desenraizamento e fragmentação contemporânea, Elias Canetti esforçou-se por pensar nesta estranha recomendação de Chamisso, buscando uma unidade mais ampla à qual o indivíduo poderia sentir-se ligado: nem unidade geográfica, nem fronteiras, nem a língua - embora a familiaridade de palavras fosse útil em situações difíceis; nem a história, pois "as figuras e os momentos que the penetravam a consciência" estariam "além de tudo o que o historiador metódico concebia como história". O sólido da sombra, para Canetti, estava num sujeito histórico que, a rigor, ainda não existia no projeto iluminista de Chamisso: as massas e os símbolos de massa cujos traços mais salientes seriam: "a densidade, o crescimento e a abertura para o infinito, a coesão surpreendente e notável, o ritmo comum e a descarga súbita". Canetti diagnosticava assim, na sua notável impermanência, o intrincado campo da nacionalidade, situado nos limiares pouco visíveis da coletividade e da memória (Canetti 1960: 168-9).

Ernest Renan dizia que "a essência de uma nação é que os indivíduos tenham muitas coisas em comum e, também, que todos tenham esquecido muitas coisas". Era uma referência irônica à quantidade de invenção e imaginação contidas neste fenômeno que ainda resiste à modernidade: a nação. Não há talvez símbolo mais impressionante da nação como uma comunidade imaginada do que os famosos Túmulos de Soldados Desconhecidos, existentes em diversos países. Nenhum impertinente se atreve a perguntar a respeito da "nacionalidade" do soldado desconhecido, pois é óbvio que seja francês, norte-americano ou argentino, conforme o país no qual esteja edificado o monumento. Porque, para além da conceituação propriamente política, tais monumentos constituem um retrato da nação como aquela comunidade imaginada ou inventada, que permanece, em camadas profundas, na mentalidade coletiva dos povos e resiste às agitações de superfície da história.

Surgindo em meio da atmosfera da Revolução Francesa, a nação foi pensada sobretudo como um conceito político territorial, cuja base era a existência de uma lei comum e de um corpus de cidadania - era a "naçãocontrato", aquela que, segundo o mesmo Renan, nascia do "plebiscito de todos os dias". A isto se contrapôs uma concepção mais cultural de nação, formulada pelas diversas correntes do historismo romântico - uma "nação-instinto", o espírito ou caráter peculiar de um povo ou comunidade, que passou a ser visto como fonte de valores e de conduta. Parece óbvio que estas duas matrizes do fenômeno nacional simplificaram demasiado a questão, transformando-a numa camisa-de-força de enorme pobreza heurística. Ainda assim, este dualismo conceitual parece ter adquirido uma certa força que foi muito além da sua mera funcionalidade metodológica. $\bigcirc$ imaginário nacional náo é, decididamente, o que parece e, sobretudo, não é aquilo que parece ser a si próprio.

Acostumamo-nos a ver a nação como algo mais racional, sem perceber que, como entidade transcendente, ela veio substituir tanto a figura imanente do soberano quanto a própria substância temporal do reino dinástico. Já na atmosfera revolucionária da "naçāo sublevada" em 1789, o Abade Sieyès, num panfleto famoso, exemplificava esta transferência da soberania do rei para a nação: "A nação é anterior a tudo. Ela é a fonte de tudo. Sua vontade é sempre legal. O modo como uma nação exerce sua vontade não importa; o fato é que ela a exerce; qualquer procedimento é adequado e sua vontade é sempre a lei 
suprema". O que se configura neste texto muito citado e pouco entendido, é um processo de substituição da figura imanente do soberano, o rei, para uma identidade coletiva e transcendente, a nação. Sabemos que nem o iluminismo, inglês ou francês, este último sem uma teoria política sistemática, autorizavam essa nova idéia agigantada de soberania - urdida mais pelos políticos da "nação sublevada", como Robespierre ou Saint-just do que, propriamente, pelos filósofos. Esta superestimação mística - decididamente messiânica na clássica análise de J. L. Talmon - configurava antes um deslizamento da idéia de soberania intrínseca à monarquia absoluta, que é repassada para o Terceiro Estado e amplificada. Tanto que o crime primordial do antigo regime, o crime de "lesa-majestadade", será reposto nas novas Constituições como crime de "lesanação" (Sevcenko 1989). A partir daí, foi possivel delinear a nação num quadro muito mais difuso e complexo mas que certamente ultrapassava de muito a esfera propriamente política, associada de forma renitente à racionalidade.

Gellner já reconhecia esta substância culturalmente criativa, positivamente inventiva do ardor nacionalista. É o nacionalismo que dá origem às nações, e não o contrário - ele se utiliza, e sempre se utilizou, da proliferação das culturas ou da riqueza cultural preexistente, historicamente herdadas, embora o faça seletivamente e muito freqüentemente as transforme de maneira radical. $O$ nacionalismo, em princípio, não é nem contingente nem acidental, mas mostra como foi possível revivificar línguas mortas, inventar tradições e restaurar antigas essências, algumas bastante fictícias (Gellner 1983).

Benedict Anderson, foi um dos autores que procurou compreender todo - imaginário ligado à nação colocando-a lado a lado, não com as ideologias políticas abraçadas conscientemente, mas com os sistemas culturais amplos que a precederam, a partir dos quais - bem como contra os quais - a nação passou a existir. Foi este caráter transcendente da nação que gerou o que Anderson chama de "mágica do nacionalismo": sua capacidade de transformar o acaso em destino, a fatalidade em continuidade, a contingência em significado. Para os casos específicos que Anderson analisa, dentro de sua especialidade, os países do Sudeste Asiático - os sistemas culturais relevantes que precederam a nação foram a comunidade religiosa e o reino dinástico. Anderson privilegiou, sobretudo, os destinos peculiares de suportes de difusão como o livro e o romance - respectivamente, a mercadoria impressa e o gênero literário característicos da produção cultural na modernidade (Anderson 1989). Bhabha levou mais longe a análise dos imaginários nacionalistas, discutindo-os na perspectiva das teorias tropológicas; neste caso, as próprias nações são narrativas e o imaginário nacional nasceu do poder de narrar, articular ou impedir que se formassem outras narrativas (Bhabha 1995). Contudo, sabemos que a nação, como comunidade imaginada foi construída culturalmente, não apenas através de suportes escritos mas também visuais, materiais - e toda uma ampla variedade de outros suportes que nossa época se encarrega, cada vez mais, de multiplicar.

A fabricação do imortal; memória, história e estratégias de consagração no Brasil, de Regina Abreu, é um livro que explora algumas das possibilidades desta construção cultural da nação, a partir de um ângulo privilegiado e não menos complexo daquilo que, sob um aspecto mais vasto, 
poderia ser chamado de cultura material. A doação de um coleção de objetos, pertencentes ao senador Miguel Calmon du Pin, para o Museu Nacional do Rio de Janeiro, é o ponto de partida de Regina Abreu para analisar, em todos os seus pormenores, os processos culturais de fabricação da memória brasileira. Fabricação não apenas no sentido de novas invenções mas, também e sobretudo de reforço e recriação de concepções já existentes de brasilidade. A incorporação de um viés antropológico pela autora fez com que suas análises deśvendassem, a partir do seu tema específico, esta espécie de transcendentalização do nacional e a sua permanência em estratos mais profundos do inconsciente coletivo brasileiro.

A doação ocorre no agitado ano de 1936, quando após a morte do senador Miguel Calmon - ocorrida no ano anterior - sua esposa decide doar ao Museu a maior parte dos móveis, tapeçarias, objetos artísticos, jóias, porcelanas - praticamente tudo o que fazia parte dos amplos salões da residência do casal, o palacete da Rua São Clemente, Botafogo. Os detalhes da doação já constituem, por si, dados importantes: Alice da Porciúncula, viúva de Miguel Calmon exigia, por exemplo, que a coleção de objetos e relíquias nunca fosse desmembrada e que "a arrumação, classificação e conservação" ficasse sob os seus cuidados pessoais. A disposição dos objetos numa sala especial era uma forma de Miguel Calmon ingressar no panteão da memória de outros heróis brasileiros, imortalizados na dimensão de suas trajetórias públicas - sobretudo porque, na sua discrição de esposa, Alice Calmon fizera quase que um assepsia total da coleção, depurando-a de quaisquer referências tanto a si própria quanto à vida privada do Senador. Quase todas as peças e objetos transferidos para o museu compunham os salões da residência, locais públicos da casa que funcionavam quase que como extensões dos gabinetes e locais de trabalho.

Outra figura interessante, também presente neste livro, é a de Gustavo Barroso, integralista e autor de vários livros anti-semitas - que procurava fazer do Museu Nacional um espelho de suas próprias concepções pessoais de brasilidade. Barroso já sugeria, numa carta a Alice Calmon, que a incorporação da referida coleção ao Museu seria uma forma do ilustre Senador fazer sua entrada naquela que seria a "Casa do Brasil".

Barroso encarava o Museu como um repositório das autênticas tradições nacionais, derivadas na sua totalidade do Estado Imperial e, por extensão, da nobreza européia. Daí sua ênfase numa exposição onde predominavam objetos da elite brasileira, consagrando a história como uma galeria de esplêndidos retratos. "O Museu repetia ritualmente, por intermédio de seus objetos, a balada exemplar dos heróis", observa Regina. Neste aspecto, Barroso apenas exemplificava o seu desagrado explícito em relação ao artificialismo da la. República e a contrapartida integralista de que bastava "substituir as oligarquias broncas pelas oligarquias esclarecidas". Por outro lado, Barroso parecia reiterar uma forma de conceber a história brasileira e o figurino imaginário da nação, como organismos presos à uma temporalidade vazia e homogênea - que, na acepção romântica foi caracterizada como uma "idolatria da história". Esta concepção de história, subjacente à estratégia pessoal de Barroso na organização museológica - tão bem analisada por Regina Abreu pareceu-nos um pouco distante da visão fortemente conspiratória exposta em livros 
como Brasil, colônia de banqueiros e História secreta do Brasil, publicados alguns anos antes de 1936. A análise das concepções de Barroso, projetadas nas suas estratégias de montagem das exposições - que a autora desenvolve com grande sensibilidade - já fornece, a nosso ver, um fértil contraponto com a "idolatria da história", talvez a característica mais saliente do compulsivo discurso verbal de Barroso. Contraponto essencial, por exemplo, para relativizar certas análises já consolidadas, de cunho mais intrínseco ao discurso verbal de Barroso que, passando ao largo das peculiaridades brasileiras, caracterizam-no como crítico do individualismo derivado da Revolução Francesa para depois enquadrá-lo numa certa forma de messianismo romântico ou ideologia "do capitalismo hipertardio" (Rago 1989). Mas um tal contraponto já sugere a necessidade de novas pesquisas sobre um tema que valeria a pena retomar, sobretudo a partir destes novos eixos narrativos da história brasileira, desdobrados do mergulho de A fabricação do imortal no vasto campo da cultura material.

Utilizando-se da análise de Pomian, a autora oberva o quanto a coleção Miguel Calmon significava a representação de um homem através dos seus objetos semióforos. Neles estariam representados o homem em toda sua extensa vida pública, a tradição da nobreza de sangue nos ideais familiares ou a atuação do engenheiro e do homem de ciência em prol da modernização do país. Estes eixos de representação nos são mostrados através de um cruzamento de elementos da trajetória biográfica de Miguel Calmon com os objetos materiais da coleção.

Metal nobre e árvore genealógica - as duas metáforas servem para a autora - inspirada em Simmel -, analisar o significado de alguns objetos centrais da coleção Miguel Calmon. Mas há duas particularidades no ethos da nobreza brasileira, desenvolvidas e modificadas no fluxo temporal da história, sobre as quais também seria conveniente pensar a coleção Miguel Calmon. Em primeiro lugar, a permeabilidade que permitiu ao rarefeito nobre brasileiro, como herança da nobreza lusitana, a sobrevivência, em situações históricas bastante difíceis situações que exigiram mais uma adaptabilidade do que uma auto-suficiência ou centramento nos próprios interesses. Em segundo lugar, aquilo a que poderíamos chamar de dezenraizamento, embora muitas vezes possa ser entendida como ausência de tradição; mais do que apenas uma preocupação exclusiva por identidade, diríamos que, da perspectiva dos agentes, ela se expressaria muito mais por uma angústia pela ausência de tradição, atitude que buscaria compensações num passado imediato ou remoto.

A coleção Miguel Calmon, com seus objetos semióforos, escreve Regina Abreu, "sinaliza a fundação das elites políicas na República" (p.45). Sendo a maior parte dos objetos proveniente das casas reais européias, dinastias chinesas e antigos castelos franceses - elas não expressariam, para além da tipologia de Simmel, também aquele dezenraizamento e ansiedade pela ausência de tradição, peculiar à nobreza brasileira? $\bigcirc$ que faz lembrar a muito célebre observação de Octavio Paz de que "na Europa, a realidade precedeu o nome. A América, pelo contrário, começou por ser uma idéia" ou uma "vitória do nominalismo: o nome engendrou a realidade". Paz chamou a tudo isto de Literatura de fundação (Paz 1961). Examinando as peças da coleção Calmon, seus destinos posteriores e ulteriores, seus lugares nas estratégias de conservação 
- tão bem estudados no livro - somos tentados a vê-los também como relíquias ou "objetos de fundação".

A nação, este "misto de individuo-coletivo e de coletivo de indivíduos" - definição que a autora empresta de Louis Dumont - é ilustrada, de forma convincente, pela própria trajetória de Miguel Calmon que se confunde com a própria República. Abstraindo-nos da noção estática de identidade, A fabricação do imortal lembra-nos o quanto ainda somos herdeiros de um estilo de brasilidade, segundo o qual o indivíduo é definido pela nação, a qual, por sua vez, extrai sua autoridade de uma tradição supostamente comum e tacitamente admitida. A atuação de Miguel Calmon como engenheiro e "homem de sciencia", registradas nos objetos, se configura em dois eventos marcantes de sua afuação e, por extensão, da própria história republicana: as expedições da "Missão Rondon" e a Exposição Nacional do Centenário de 1908. O conjunto de fotografias doadas ao Museu sobre estes dois eventos, algumas delas reproduzidas em $A$ fabricação do imortal, constituem um legado precioso. Observando a bonomia dos fotografados, suas posiçōes algo estudadas, índios vestidos de uniforme militar, meninas índias alinhadas com as salesianas e com a bandeira nacional ao fundo, a bizarrice do índio bororo todo enfarpelado num terno - sentimos, ainda que difusamente, a construção tácita de um sentimento de brasilidade através de um novo eixo narrativo. A fundação da República dar-se-ia pela incorporação da ciência e da técnica à tradição unificadora das elites imperiais - sendo que a trajetória pública de Miguel Calmon adquiria características de um autêntico elo de ligação entre os dois fluxos temporais.

O Museu Nacional sinalizava uma visão do passado calcada na relação de continuidade do Brasil enquanto nação com o Estado patrimonialista português. A valorização de uma etnia peculiar, autóctone, que incorporava, ainda que por meio de uma representação paralela, a do folclore nacional negros, índios e mestiços - jogava com uma notável ambigüidade, sempre hesitante entre um nacionalismo assimilacionista ou um nacionalismo excludente, todos se colocando como expressões legítimas e genuínas do instinto local. Porque em 1936, a imagem mental da nação conflui para uma necessidade difusa de organização e hierarquização que se projeta em direção ao passado. Projeção que se faz - seja qual for o suporte de memória - de forma sempre seletiva: em nenhum momento se mencionam eventos bastante recentes da história do país - por exemplo, nenhuma menção à chusma de imigrantes que, literalmente, vêm tumultuar a cena social brasileira na la. República. A incorporação da coleção Miguel Calmon ao Museu Nacional, neste sentido, apenas confirmava a necessidade de se forjar novos laços simbólicos para a nação: através daquele novo repertório de objetos semióforos, não se tratava mais de confrontar o nacionalismo com $\circ$ cosmopolitismo, como no período de consolidação da República, mas de entabular e sinalizar uma nova antítese entre um matiz de nacionalismo assimilacionista, contra outro, mais intransigente.

Sob um aspecto mais extenso pode-se notar aí aquela transposição da unidade nacional - com sua vaga sugestão de harmonia de interesses - para a construção mítica de um organismo, em cujo vértice estaria, por exemplo, não apenas o individuo mas também a família e o Estado. Schandler mostrou, numa 
análise das "metáforas do organismo", o quanto a totalidade da estrutura orgânica é extremamente dinâmica, com deslizamentos de sentidos, sobreposições e fusões que nunca se excluem (Schandler 1971).

A fabricação do imortal mostra, com abundância de detalhes, o quanto o Museu Nacional, mesmo sendo naquele período o "Museu do Barroso", veio cumprir o seu papel como "lugar de memória" da brasilidade. Regina Abreu se utiliza - com muita pertinência - da primeira abordagem que Pierre Nora faz desta noção em les lieux de mémoire. Concebido como um eixo em torno do qual se cristaliza uma parte importante da memória nacional, o próprio Nora alargou desmesuradamente a aplicação do conceito, chegando a considerar "lugar de memória" como "nova categoria de inteligibilidade da história contemporânea" (Nora 1993). Mas não é possível chegar a tanto sem esconder o sentimento de ambigüidade existente por trás do uso desta categoria conceitual. Basta comparar as observaçōes diferenciadas que o próprio autor faz na parte introdutória dos vários volumes da obra, para perceber o quanto ele mesmo hesita entre considerar "lugar de memória" como parte das formas de representação ou - como preenchendo totalmente o campó do simbólico². Neste aspecto, parece-nos que Nora se aproxima daquele equívoco formidável - do qual nem sempre nos livramos facilmente - que é o de considerar as representações humanas como sendo apenas simbólicas (Neiva, 1993). O que mostra que para tornar mais heurística a noção de "lugar de memória", o debate ainda deve avançar sobretudo neste recorte de geometria muito variável que é o imaginário nacional, tão carente de tratamentos mais sistemáticos e interdisciplinares. Nem é preciso dizer que, neste sentido, A fabricação do imortal representa uma enorme contribuição, tanto mais porque calcada numa análise da cultura material.

Densa e ampla sondagem do universo material e mental das elites brasileiras, A fabricação do imortal se inscreve na tendência recente da historiografia de esforçar-se por inverter a relação entre Memória e História partindo da primeira para a segunda - e contribuindo, a seu modo, para retirar a memória política da brasilidade, do seu estranho universo, dentro do qual, como disse Renan, "todos os homens talvez tenham esquecido muitas coisas" este universo algo romantizado, feito daqueles "ritmos comuns e descargas súbitas", cheio de sortilégios, quando não fortemente irracional.

\section{BIBLIOGRAFIA CITADA}

ANDERSON, Benedict. Nação e consciência nacional. Tradução por Lólio Lourenço de Oliveira. São Paulo: Ática, 1989.

BHABHA, Homi K. DissemiNation: time, narrative, and the margins of the modern nation. In: BHABHA, Homi K. (ed.) Nation and narration. New York: Routledge, 1995.

CANETTI, Elias. Massa e poder. Tradução por Sérgio Tellaroli. São Paulo: Companhia das Letras, 1995. (1.ed. 1960).
2. Veja-se o que Nora escreveu sobre os "lugares de memória", no to mo II ("La Nation"), vol.1, ("Héritages, historiographie, paysages"), p.X: "É que a Naçào é inteiramente uma representação. Ela não é nem um regime, nem una política, nem uma doutrina, nem uma cultura, mas sim o palco de todas as expressöes desses elementos, uma forma pura, uma fórnnula imutável $e$ mutável de nossa comunidade social, como, sem dúvida, de todas as comunidades sociais modernas". E, depois, no bem mais recente tomo III, ("Les Frances"), vol.1, ("Conflits et partages"), p.22: "A França se encontra inteiramente ao lado da realidade simbólica; ela não tem outro sentido, através das múltiplas peripécias de sua história e de suas formas de existência, que não o simbólico". Discutindo ainda a noção de historicidade dos "lugares de memória", contida em Nora - e relativizando a noção de um passado patrimonializado (ou reificado) nos museus, monumentos $e$ instituições - veja-se Hartog (1995). 
CHAMISSO, Adelbert von. A bistória maravilhosa de Peter Schlemibl. Tradução por Marcus Vinicius Mazzari. São Paulo: Estação Liberdade, 1989. (1.ed. 1813).

DOSSE, François. L'Empire dus sens: l'humanisation des sciences humaines. Paris: La Découverte, 1995.

HARTOG, F. Comment écrire l'Histoire de France? Annales ESC, v.50, n.6, p.1218-26, nov./déc. 1995.

NEIVA, Eduardo. Imagem, História e Semiótica. Anais do Museu Paulista: História e Cultura Material, São Paulo, N. Sér., n.1, p.11-30, 1993.

NORA, Pierre. Les lieux de mémoire. Paris: Gallimard, 1984,1986,1993. 3t.

PAZ, Octavio. Signos em rotação. São Paulo: Perspectiva, 1990.

RAGO FILHO, Antonio. A crítica romântica à miséria brasileira: o integralismo de Gustavo Barroso. São Paulo, 1989. Dissertação (Mestrado) - Pontifícia Universidade Católica.

SALIBA, Elias Thomé. Viagem às utopias românticas. Rio de Janeiro, Fundação RioArte, Revista do Brasil, ano 4, n.10, p.62-70, 1989

SEVCENKO, Nicolau. Aspectos irracionais do Iluminismo. Rio de Janeiro, Fundação RioArte, Revista do Brasil, ano 4, n.10, p.19-31, 1989.

SCHANDLER, Judith E. Les métaphores de l'organisme. Paris: Vrin, 1971.

TALMON, J. L. Political Messianism: the romantic phase. London: Secker \& Warburg, 1960. 
À sombra do imortal: reflexões sobre a nação e a memória

Elias Thomé Saliba

A partir do livro de Regina Abreu, A fabricação do imortal: memória, história e estratégias de consagração no Brasil, são discutidas as principais abordagens da problemática da nacionalidade. O tema central do livro é a coleção Miguel Calmon du Pin, doada ao Museu Nacional em 1936, que é analisada nos seus mais variados desdobramentos, tanto no que se refere às estratégias de consagração individual quanto às formas de construção cultural da brasilidade.

UNITERMOS: Museu histórico. Coleções históricas. Miguel Calmon. Museu Histórico Nacional.

Anais do Museu Paulista, N.Sér. v.4, p.309-16, jan./dez.1996

Under the aegis of the immortal: reflexions on nation and memory

Elias Thomé Saliba

Taking Regina Abreu's book, A fabricação do imortal: memória, história e estratégias de consagração no Brasil, as a starting point, the A. discusses the main approaches to the issues of nationalism and memory. The core of this book is the grant made to the National History Museum in 1936 by Miguel Calmon du Pin of his collection which is analysed according to the strategies of personal consecration and to the vectors for the cultural construction of "brasilidade" (Brazilianness").

UNITERMS: Historical collections. Historical museums. Miguel Calmon. Museu Histórico Nacional

Anais do Museu Paulista, N.Sér. v.4, p.309-16, jan./dez.1996 